\title{
Fallo renal agudo en varón joven con celulitis en extremidad inferior
}

\author{
A. RODRÍGUEZ LORENZO, F. MARTELO VILLAR \\ Servicio de Cirugía Plástica y Quemados. Complejo Hospitalario Universitario Juan \\ Canalejo. A Coruña
}

ACUTE RENAL FAILURE IN A YOUNG MALE WITH CELLULITIS IN

THE LOWER LEG

\begin{abstract}
RESUMEN
La fascitis necrotizante producida por el Streptococo pyogenes presenta una mortalidad elevada. Habitualmente el reto supone detectar la infección antes de que el cuadro progrese al denominado síndrome de shock tóxico posestreptocócico, ya que entonces las medidas terapéuticas resultan frecuentemente ineficaces. En la secuencia de eventos en la progresion de la infección a shock es frecuente la presencia de insuficiencia renal previa a la hipotensión. Presentamos un caso clínico de un paciente de 38 años que desarrolló una fascitis necrotizante fulminante por Streptococo pyogenes cuya sintomatología al ingreso hospitalario fue la presencia de celulitis en extremidad inferior asociada a fallo renal.
\end{abstract}

PALABRAS CLAVE: Fascitis necrotizante. Streptococo piogenes. Sindrome del shock tóxico estreptococico. IInsuficiencia renal aguda.

\begin{abstract}
Necrotizing fascitiis due to Streptococcus Pyogenes has a high mortality rate. Detection of the infection before it developes to the streptococcal toxic shock syndrome is quite challenging and its one of the main goals of its management because at this final stage the treatment is in most of the cases ineffective. In a secuence of events of the progression of the infection to shock, renal failure occurs before hipotension very often. We report the case of a 38-year-old patient affected by a fulminant necrotizing fascitiis by Streptococcus Pyogenes which presented at admission with lower leg cellulitis and acute renal failure.
\end{abstract}

KEY WORDS: Necrotizing fascitiis. Streptococcus pyogenes. Streptococcal toxic shock syndrome. Acute renal failure.

Rodríguez Lorenzo A, Martelo Villar F. Fallo renal agudo en varón joven con celulitis en extremidad inferior. An Med Interna (Madrid) 2008; 25: 291-293.

\section{INTRODUCCIÓN}

No existe ningún dato patognomónico de la fascitis necrotizante producida por Estreptococo del Grupo A, no obstante diferentes datos locales y sistémicos nos orientan a su diagnóstico $(5,6)$. Quizás el síntoma más precoz sea el dolor desproporcionado a la apariencia de la infección cutánea, habitualmente secundaria a una pequeña herida o traumatismo previo. La presencia de un edema indurado extendiéndose más allá del área de eritema es otro signo local habitual, siendo infrecuente la presencia de linfangitis. La presencia de cambios cutáneos debidos a trombosis de vasos subcutáneos, suelen producirse posteriormente, yendo de una piel brillante y tensa inicialmente a purpuracea y grisácea, frecuentemente asociado a la formación de bullas rellenas de líquido serosanguinolento. Las pruebas de imagen pueden revelar un aumento de partes blandas y la presencia de gas en los tejidos sugiren una etiología diferente como infección por clostridium, celulitis anaeróbico no-clostridium o fascitis necrotizante tipo 1. Entre las manifestaciones sistémicas la fiebre es hallazgo consistente asociada a una elevada leucocitosis con desviación izquierda y la presencia de valores elevados de CPK sugieren una infección profunda de tejidos blandos, no obstante en ocasiones puede existir leucopenia. La progresión de CPK es un dato orientativo correlacionado con la progresión de la infección. Bisno y Stevens (7) establecen tres fases clínicas del SSTE. En la fase 1, se detectan síntomas precoces de SSTE que incluyen mialgia, escalofríos, fiebre, náuseas, vómitos y diarrea, acompañados por dolor el el sitio de trauma menor. En la fase 2, taquicardia, fiebre y taquipnea y aumento del dolor en el sitio de la infección. En la fase 3, la presencia de fiebre persistente, dolor incoercible en el lugar de la infección y evidencia de shock y fallo multiorgánico. La hipotensión está presente en el 40-50\% de los pacientes en el momento del ingreso hospitalario y el resto la desarrollan en las siguientes 4-8 horas de evolución. Frecuentemente, la insuficiencia renal precede a la hipotensión, como se refleja en el presente caso clínico aportado. Presentamos un caso clínico de paciente joven que desarrolló una fascitis necrotizante fulminante por Estreptococo pyogenes, cuyo debut clínico fue un

Trabajo aceptado: 18 de febrero de 2008 


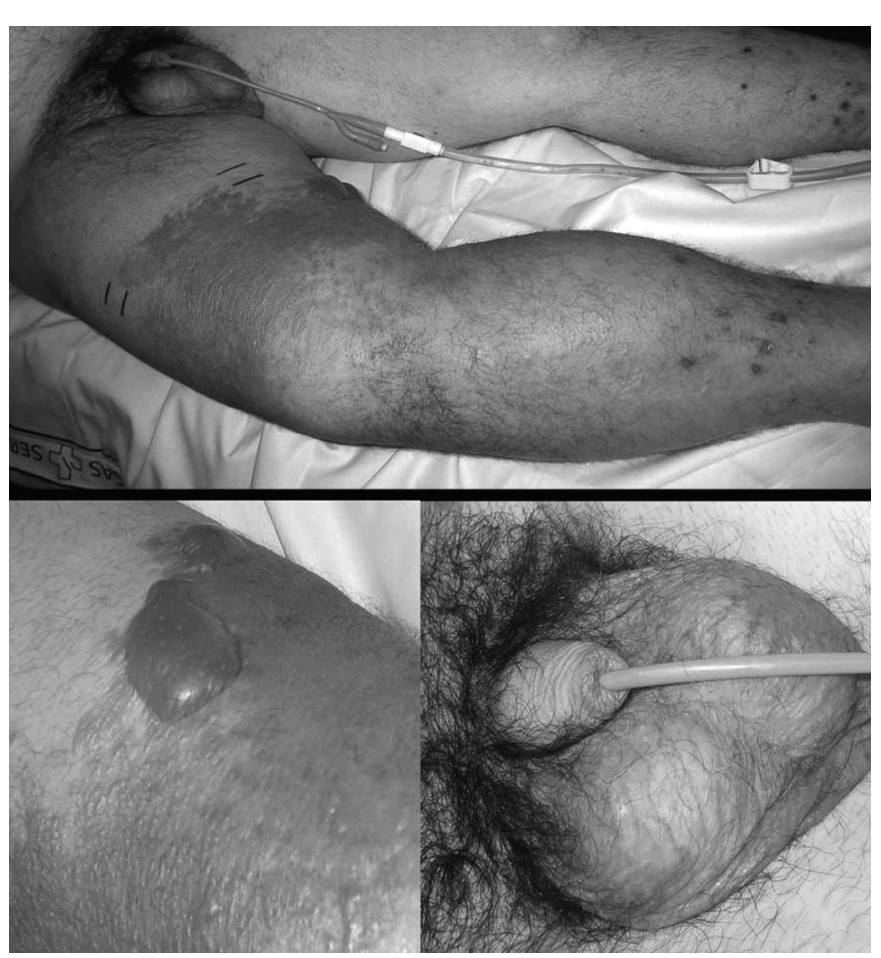

Fig. 1. Apariencia de las lesiones cutáneas a las 24 horas de ingreso con celulitis, ampollas y anestesia cutánea hasta tercio medio de muslo derecho y afectación escrotal.

fallo renal agudo asociado a celulitis en extremidad inferior. Adicionalmente revisamos la literatura sobre la etiopatogenia, diagnóstico y tratamiento de este cuadro.

\section{CASO APORTADO}

Varón de 38 años de edad alérgico a penicilina, bebedor de 80 gramos de alcohol/día y obeso acude al servicio de urgencias de nuestro hospital por presentar un cuadro de edemas en las extremidades inferiores, distensión abdominal y febrícula de dos días de evolución. Refiere además astenia importante de varias semanas de evolución acompañada de náuseas, vómitos y diarrea en los últimos 7 días. A la exploración física destaca la presencia de $37,5^{\circ} \mathrm{C}$ de temperatura, datos de ascitis abdominal y edemas en ambas extremidades inferiores principalmente en la derecha asociado en este miembro a eritema , petequias y equímosis. No se aprecian otros datos patológicos a la exploración. En la analítica de ingreso se obtuvieron los siguientes resultados: Hemoglobina 8,3 gr/dl; Hto: 23,3\%; Leucocitos 20.420 por $\mu \mathrm{l}$ (neutrófilos 91,5\%); Plaquetas 119.000 por $\mu \mathrm{l}$; Dimeros D $14.080 \mathrm{ng} / \mathrm{dl}$; Urea: $178 \mathrm{mgr} / \mathrm{dl}$; Creatinina $9 \mathrm{mgs} / \mathrm{dl} ; \mathrm{Na} 124 \mathrm{mEq} / \mathrm{l}$; K 3,9 mEq/l; Proteinas totales 5,6 gr/dl, LDH $559 \mathrm{UI} / \mathrm{l}$; CPK 239 UI/l; GPT 35 UI/l; GOT 77 UI/l. Se realizó una radiografía de tórax que era normal y una Ecografía y TAC abdominal que reflejaban una ascitis masiva, datos de hepatopatia crónica y esplenomegalia. Con el juicio clínico de insuficiencia renal aguda, en el contexto de un hepatópata crónico de origen enólico, y celulitis en extremidad inferior ingresa en el servicio de nefrología. Se instaura un tratamiento con diuréticos (furosemida) y antibioterapia empírica con ciprofloxacino (1 gramo/24 horas) tras extracción de hemocultivos.

A las 24 horas del ingreso el paciente presenta fiebre $\left(38,4{ }^{\circ} \mathrm{C}\right)$ y empeoramiento de las lesiones en el miembro inferior derecho con aumento del dolor, extensión de celulitis y presencia de ampollas.En la analítica se objetiva un empeoramiento en la función renal con valores de creatinina plasmática de $10,60 \mathrm{mg} / \mathrm{dl}$ y urea $181 \mathrm{mg} / \mathrm{dl}$, aumento de la leucocitosis ( 35.340 por $\mu 1$, neutrófilos $96,8 \%$ ) y alteración en la coagulación (tiempo de protombina de 28,8 segundos y tiempo de tromboplastina parcial activada de 61,4 segundos).En el hemocultivo realizado al ingreso se aisla Estreptococo Pyogenes por lo que se inicia antibioterapia intravenosa con clindamicina y gentamicina y es ingresado en la UCI por presentar inestabilidad hemodinámica.La progresión de las lesiones en extremidad inferior es rápida por horas, presentando anestesia cutánea y grandes ampollas hasta el tercio medio de muslo y afectación escrotal (Fig. 1). Se realiza entonces el diagnóstico de Síndrome de Shock Tóxico Estreptocócico tras fascitis necrotizante por Estreptococo Pyogenes. El paciente precisa ventilación mecánica invasiva, aminas vasoactivas y hemofiltración venovenosa contínua y indicándose intervención quirúrgica urgente en la que se realiza desbridamiento escrotal, desbridamiento de fascia hasta raíz de muslo y amputación abierta supracondílea.

Presenta una evolución posoperatoria desfavorable con fracaso multiorgánico (fracaso renal agudo, coagulopatia y síndrome distrés respiratorio agudo) no respondiendo a medidas de soporte hemodinámica ni antibioterapia, falleciendo finalmente a las 24 h de la cirugía.

\section{DISCUSIÓN}

El Streptococcus pyogenes o Streptococcus Beta-Hemolítico del grupo A es un coco Gram-positivo aeróbico facultativo que crece en cadenas y cuyo único reservorio conocido en la naturaleza es la piel y mucosa humanas. Produce un amplio espectro de infecciones en humanos incluyendo faringitis, amigdalitis, fiebre escarlatina, fiebre reumática, glomerulonefritis posestreptocócica y diferentes infecciones de tejidos blandos como pyoderma estreptocócico, erisipela y celulitis. Menos frecuentemente produce lo que se denominan infecciones invasivas definidas por la presencia de bacteriemia, neumonía o cualquier otra infección asociada con el aislamiento de EGA en un medio habitualmente estéril, incluyendo entre ellas la fascitis necrotizante y la miositis gangrenosa espontánea. La prevalencia de estas infecciones invasivas según estudios prospectivos poblacionales se establece entre 1-5 casos por cada 100.000 habitantes $(1,2)$. Un tercio de ellas se complican con el llamado Síndrome de Shock Tóxico Estreptocócico (SSTE) definido por la presencia de una infección invasiva por Estreptococo Pyogenes asociada a shock y fallo multiorgánico, presentando una tasa de mortalidad que oscila entre el 30 y el $70 \%$ de los casos según las series publicadas $(2,3)$.

Los mecanismos patogénicos del SSTE no se conocen con exactitud ya que se basan en interacciones complejas entre los mecanismos de defensa del huésped y los factores específicos de virulencia del EGA(4). Como consecuencia de esta interacción el sistema inmune desencadena la liberación de grandes cantidades de citoquinas inflamatorias (Factor de necrosis tumoral $\alpha$, interferon gamma, interleukina- $1 \beta$, interleukina- 6 , interleukina-2, interferon $\gamma$, factor de necrosis tumoral $\beta$ ). Esta masiva liberación de citoquinas se establece como el posible mecanismo que explique el shock y el fallo multiorgánico que se produce el el SSTE debido a un aumento de la permeabilidad capilar y daño tisular. El manejo óptimo del SSTE tras fascitis necrotizante por EGA incluye un desbridamiento quirúrgico agresivo, antibioterapia y soporte hemodinámico. No obstante, el diagnóstico precoz supone un reto para médicos y cirujanos, siendo frecuentemente confundido este cuadro con una infección leve como celulitis. Las medidas terapéuticas 
que presentan un alto grado de recomendación clínica [basados en estudios con un nivel de evidencia científica 1b (8)] son la exploración y desbridamiento quirúrgico precoz y agresivo asociado a un tratamiento antibiótico empírico de amplio

\section{Bibliografía}

1. O’Brien KL, Beall B, Barrett NL.Epidemiology of invasive group A streptococcus disease in the United States, 1995-1999 Clin Infec Dis 2002; 35: 268

2. Davies HD, McGeer A.,Schwartz B. Invasive group A streptococcal infections in Ontario, Canada. N Engl J Med 1996; 335: 547-54.

3. Stevens DL, Tanner MH, Winship J. Reappearance of scarlet fever toxin A among streptococci in the Rocky Mountain West: Severe groupA streptococcal infections associated with a toxic shock-like syndrome. N Engl J Med 1989; 321: 1-7.

4. Stevens DL. Invasive group A streptococcus infections. Clin Infec Dis 1992; 14: 2-13 espectro que debe incluir la clindamicina, y una vez aislado el germen en cultivo, con clindamicina (900 mgs intravenosos cada 8 horas) asociada a penicilina ( 4 millones de unidades intravenoso cada 4 horas).

5. Stevens DL. The Flesh-Eating Bacterium: What's Next? N Engl J Med 1999; 179 (Supl. 2): 366-74.

6. Stevens DL. Epidemiology, clinical manifestations and diagnosis of streptococcal toxic shock syndrome. Up to date 2006; 14: 1-8.

7. Bisno AL, Stevens DL. Streptococcal infections of skin and soft tissues. N Engl J Med 1996; 334: 240-6.

8. Stevens DL. Treatment of streptococcal toxic shock syndrome. Uptodate 2006 ; $14: 1-9$

9. Rodríguez A, Midón J, Martelo F. Síndrome de Shock Tóxico Estreptocócico tras fascitis necrotizante por Estreptococo Pyogenes. Revista de Cirugía Plástica Iberolatinoamericana. En impresión. 